\title{
Editorial: Multidisciplinary Geophysical Imaging of Volcanoes
}

\author{
Pier Paolo Bruno ${ }^{1 *}$, Gaetano Festa ${ }^{2}$ and Jean Vandemeulebrouck ${ }^{3}$ \\ ${ }^{1}$ Dipartimento di Scienze della Terra, Ambiente e Risorse, Università di Naples Federico II, Naples, Italy, ${ }^{2}$ Dipartimento di \\ Fisica Ettore Pancini, Università di Naples Federico II, Naples, Italy, ${ }^{3}$ Univ. Grenoble Alpes, Univ. Savoie Mont Blanc, CNRS, \\ IRD, IFSTTAR, ISTerre, Grenoble, France
}

Keywords: geophysical imaging, geophysical observations, volcanic structure, volcano dynamics, novel techniques

Editorial on the Research Topic

\section{Multidisciplinary Geophysical Imaging of Volcanoes}

Great strides have been made in the geophysical imaging of volcanic systems on a wide range of spatial scales. Progress has included data and instrumentation advances, application of new techniques, and improvement in computational capabilities. The goal of this Research Topic is to highlight the imaging capabilities of geophysical methods in characterizing the internal structure and the dynamics of volcanoes, toward an understanding of ongoing and potential eruptions, and to improve time-dependent estimation of related hazards.

The majority of the contributions focused on Solfatara Volcano, the most active area of Campi Flegrei, which is experiencing an unrest in the recent years and that is becoming a natural laboratory for testing new methods and applications. Indeed, three contributions analyse active time-lapse seismic data recorded in a 2D and 3D geometry during the first Repeated Induced Earthquake and Noise experiment (RICEN: Festa et al., 2015), conducted from September 2013 to November 2014. De Landro et al., for instance describe a methodology based on the estimation of the quality factor Q from the RICEN active seismic data to obtain a high-resolution attenuation model of the very shallow subsurface. They found low $P$-wave quality factor $\left(Q_{P} 5-40\right.$ in the near-surface layer $30 \mathrm{~m}$ thick) in shallowest subsoil of Solfatara, which globally increases with depth in the explored volume and shows a strong lateral heterogeneity. Within the well-resolved central portion of the explored volume the $Q_{P}$ model shows features consistent with the hydrothermal fluid distribution within Solfatara.

Scala et al., using the 3D active seismic data from the RICEN experiment analyzed instead the scattering properties of the Solfatara crater to evaluate the ratio between coherent and incoherent intensities. The scatterers are interpreted as regions richer in water with respect to the background and eventually due to the condensed steam running below the investigated area. The connection between the scattering mean free path and the type, and content of fluids retrieved here is of fundamental importance to image the volcanic structure: upscaling this technique to a kilometric size area could allow to provide constraints about the magma chamber and related feeding mechanism.

Finally, Bernardinetti and Bruno, using two machine learning algorithms merged active 2D seismic data from the RICEN experiment (Bruno et al., 2017) with some geophysical anomalies recorded at the surface of the crater (Bruno et al., 2007). The use of unsupervised learning techniques can reduce interpretation uncertainties while interpreting multivariate data, therefore improving the understanding of the complex dynamics occurring in volcanoes. This allowed to associate surface and subsurface anomalies to different hydrothermal features such as shallow gas-saturated and water-saturated zones and their underlying fractures/faults feeding system. 
Carbonari et al., presented a sensitivity study aimed at estimating the effectiveness of continuous magnetotelluric observations for monitoring Solfatara hydrothermal system: in particular, two possible evolution scenarios of a hydrothermal system have been assumed, corresponding to an increase in fluid flow rate from the system source and permeability of the rocks hosting the fluid upwelling zone, respectively. The study has shown that continuous MT measurements are not sensitive enough to detect a significant increase in the source fluid flow rate over time intervals less than 10 years. On the contrary, if the permeability of the upwelling zone increases, a measurable change in the MT response occurs over a time interval ranging from 6 months to 3 years, depending on the extent of the permeability increase.

The remaining papers describe geophysical experiments targeting other volcanic areas: Northern Andes, Indonesia and another Italian volcano: Mt. Etna. Vargas et al., analyzed the thermal structure of the Volcanic Arc in Northern Andes, using anelastic tomography. Seismic records from 1993 to 2018 have been processed to extract coda wave attenuation parameters, that have been further converted into thermal profiles, using rock physics relationships, constrained by surface and well observations. The authors show how inferred temperature profiles can provide clues in the structure, dynamics and history of a volcanic system. The study specifically revealed that the temperature is relatively low below the volcanic arc indicating a large presence of water and hydrous minerals. The isotherms become shallower toward the North; they are interrupted by a cold body, which likely indicates a lateral change in viscosity and their shape has been also influenced by regional tectonics. Finally, thermal images suggest that the thickening of the lithosphere at the northern boundary of the region prevents from further development of the volcanic arc.

Due to the presence of many active volcanoes, the volcanic risk is particularly high in Indonesia. Monitoring of these volcanoes requires precise structural studies to recognize the potential propagation paths of magma. The area of the Agung-Batur Volcanic Complex (ABVC), part of the Sunda volcanic arc, has produced numerous historical eruptions and is the subject of a seismic tomography study in this volume by Zulfakriza et al..

\section{REFERENCES}

Bruno, P. P. G., Maraio, S., and Festa, G. (2017). The shallow structure of Solfatara Volcano, Italy, revealed by dense, wide-aperture seismic profiling. Sci. Rep. 7:17386. doi: 10.1038/s41598-017-17589-3

Festa, G., Serra, M., Amoroso, O., Bruno, P. P., Pilz, M., Roux, P., et al. (2015). RICEN: Repeated InduCed Earthquakes and Noise @Solfatara, Campi Flegrei. San Francisco, CA: AGU Fall Meeting.

Bruno, P. P., Ricciardi, G. P., Petrillo, Z., Di Fiore, V., Troiano, A., and Chiodini, G. (2007). Geophysical and hydrogeological experiments from a shallow hydrothermal system at Solfatara Volcano, Campi Flegrei, Italy: response to caldera unrest. J. Geophys. Res. 112, 1-17. doi: 10.1029/2006JB004383
The authors obtained the first local-scale study of Rayleigh wave group velocity structure and the seismic velocity structure using ambient seismic noise tomography. Seismic tomograms clearly display a low-velocity structure between Mt. Agur and Mt. Batur, corresponding to a seismicity cluster, that could be a pressurized hydrothermal system in an area of buried volcanic deposits.

Finally, the Italian volcano Etna has always been the field of original and innovative experimentation in volcano geophysics, particularly in the study of ground deformations. Bonaccorso et al., using a network of dilatometers were able to determine the strain signature of a wide variety of magmatic processes (lava fountains, explosive sequences, effusive activity) occurred between 2011 and 2018. For instance, they were able to highlight the presence of strain signals during an intrusion phase, occurring well-before the typically monitored geophysical signals. This is particularly useful for the earlywarning recognition and interpretation of the initial phase of the intrusion propagation. This study showed that a network of dilatometers effectively reinforces the methods of forecasting volcanic eruptions but also the fine understanding of magmatic processes.

\section{AUTHOR CONTRIBUTIONS}

All authors listed have made a substantial, direct and intellectual contribution to the work, and approved it for publication.

\section{FUNDING}

Some papers published in this Research Topic used data acquired under the Med-Suv project. MED-SUV has received funding from the European Union's Seventh Program for research, technological development and demonstration under the grant agreement No. 308665.

\section{ACKNOWLEDGMENTS}

We thank the Editorial Board and Editorial Office of Frontiers in Earth Sciences for the kind invitation to organize and their help in managing this Research Topic.
Conflict of Interest: The authors declare that the research was conducted in the absence of any commercial or financial relationships that could be construed as a potential conflict of interest.

Copyright (c) 2020 Bruno, Festa and Vandemeulebrouck. This is an open-access article distributed under the terms of the Creative Commons Attribution License (CC $B Y)$. The use, distribution or reproduction in other forums is permitted, provided the original author(s) and the copyright owner(s) are credited and that the original publication in this journal is cited, in accordance with accepted academic practice. No use, distribution or reproduction is permitted which does not comply with these terms. 